to the change, as they suspect the Canadian Society of Internal Medicine is engineering a mandatory extension of training for all internists.

"Our position is the college should just keep internal medicine training under four years and those who want to undergo further training can just go ahead and do that, rather than mandating everybody to take five years," says Dr. Tyler Johnston, president of the Canadian Federation of Medical Students. "That's a year of deferred income in an era where we're already experiencing very high medical student debt, and we're not sure what the evidence is that adding a year will make us better internists."

The Canadian Association of Internes and Residents echoed that concern in a recent position paper, stating that mandatory extension of training for internists would "delay entry to practice for all."

But O'Brien says the creation of a GIM subspecialty would simply give students another option, rather than force them into an extra year of training. "There's absolutely no interference. This isn't a huge change we're proposing. It's a matter of providing an opportunity for students who do want and need the additional skills," he says.

Other subspecialty groups also appear opposed to accreditation for GIM, apparently out of fear that it may prove more attractive to students than their field, or simply result in more mouths to feed from the subspecialist pie.

As Dr. Finlay McAlister, president of the Canadian Society of Internal Medicine, notes, "the pie's only so big, and any time you offer a new college-accredited subspecialty program, it's going to draw trainees away from other specialties. It's probably not politically correct to say that but I suspect that may play a role in some of the decision making."

In the event a GIM subspecialty is accredited, medical schools would have the option of offering it, as with all subspecialties. But if it is formally recognized, the training would become subject to national standards.

Eight of Canada's 17 medical schools already offer additional training in internal medicine in the form of an optional fifth year, but because that training isn't accredited, there's no national evaluation or quality standards for those programs.

"We want to have official recognition for those students that are spending the extra time and money to do the extra training, because currently they aren't getting anything to show for it," says McAlister.

O'Brien, meanwhile, is hopeful that evidence of the value of a GIM subspecialty will accrue from the successful five-year programs running in Quebec, Alberta, Saskatchewan and British Columbia.

McAlister says that accreditation would also protect those existing programs from the vagaries of fair-weather funding. "Right now the provinces that have these programs are willing to fund the unaccredited fifth year because they see training internists as a priority, but the provincial funding climates could change and not having college accreditation is a liability," he says.

The Canadian Society for Internal Medicine's most recent bid for GIM accreditation has already advanced further than a string of similar applications over the past three decades. "We've been at this for about 30 years," says O'Brien. "There had to be consensus among internists that this was necessary. We had to understand what the community needed and there needed to be some pilot models to show us how well this is going to work."

The issue will resurface before the royal college's committee on specialties in the fall. If it passes muster, it will move on to its education committee for further evaluation, and ultimately, to executive council for final approval. Lauren Vogel, Ottawa, Ont.

DOI:10.1503/cmaj.109-3306

\title{
Report calls for overhaul of US food safety system
}

Previously published at www.cmaj.ca

$\mathrm{T}$ ainted peanut butter. Poisoned cookie dough. Deadly spinach. In an era of daunting problems with food-borne disease and illness, a prestigious scientific panel is recommending that the United States government overhaul its food safety system to zero in on the riskiest foods and target limited resources where they can do the most good.

A 500-page report by a committee of the Institute of Medicine and the National Research Council recommends, among other things, that the US Food and Drug Administration (FDA) shift "from a reactive approach to a risk-based approach" to food safety, set up a central data analysis operation to more efficiently pinpoint problems and better coordinate inspection efforts with state and local governments.

The study, Enhancing Food Safety: The Role of the Food and Drug Administration, suggests the FDA is failing to keep up with new challenges and lacks the vision to ensure food safety (http://books.nap.edu/openbook.php?re cord_id=12892). While more than 15 US agencies have some role in food safety, the FDA oversees about $80 \%$ of the country's food supply, including all produce, seafood and cheeses.

The importance of bolstering food safety efforts is evident in the latest statistics on food-borne illnesses - approxi- mately 76 million people in the US are affected each year, causing more than 300000 hospitalizations and 5000 deaths, according to the report. A number of recent high-profile outbreaks have heightened public interest in the problem, including a salmonella outbreak last year that affected hundreds, was suspected of causing nine deaths and resulted in one of the largest product recalls in history.

Robert Wallace, a University of Iowa professor who chaired the committee that wrote the report, says the FDA needs to "go where the problems are, and that's why you need good data." Better data, he says, should be the basis for everything the FDA does, including "where they put inspection resources, where they put 
communication resources, where they put their scientific portfolio."

Lewis Grossman, a professor at American University's Washington College of Law who also was a member of the committee, says the FDA is taking steps in the right direction but needs "an overall systematic approach to their food safety mission. It's a bit scattershot right now."

Grossman stresses that while the government must do much to ensure food safety, consumers have to recognize that "a risk-free food supply is an impossibility."

"Everybody in the entire chain from farm to fork has a role to play," he says.

While the committee was working on its report, which includes recommendations for legislative action, members of Congress were moving ahead on their own with food safety legislation that covers some of the same ground. A bill approved by the House of Representatives last year would give the agency expanded access to records and test results and more authority to conduct recalls and increase inspections at food facilities. Similar legislation has passed a committee in the US Senate and is awaiting action by the full Senate.

Wallace says the pending legislation would address a number of problems laid out in the committee's report, but there is much more to be done. Some of the report's recommendations, he notes, can be acted upon voluntarily by the FDA. He says the report, issued in June, had been well-received by the FDA, and that "what we wish for them, they would like to have for themselves."

Wallace says the committee concluded that the nation ultimately should have a single food safety agency, but that moving toward that long-term goal could be done in an "evolutionary" manner. The report, in a look at other countries' food safety systems, notes that Canada in 1996 created the Canadian Food Inspection Agency, which provides all food inspection services and enforces standards established by Health Canada.

FDA Commissioner Margaret Hamburg welcomed the study and said in a statement that the FDA is working through President Barack Obama's yearold Food Safety Working Group to ensure all government agencies with a

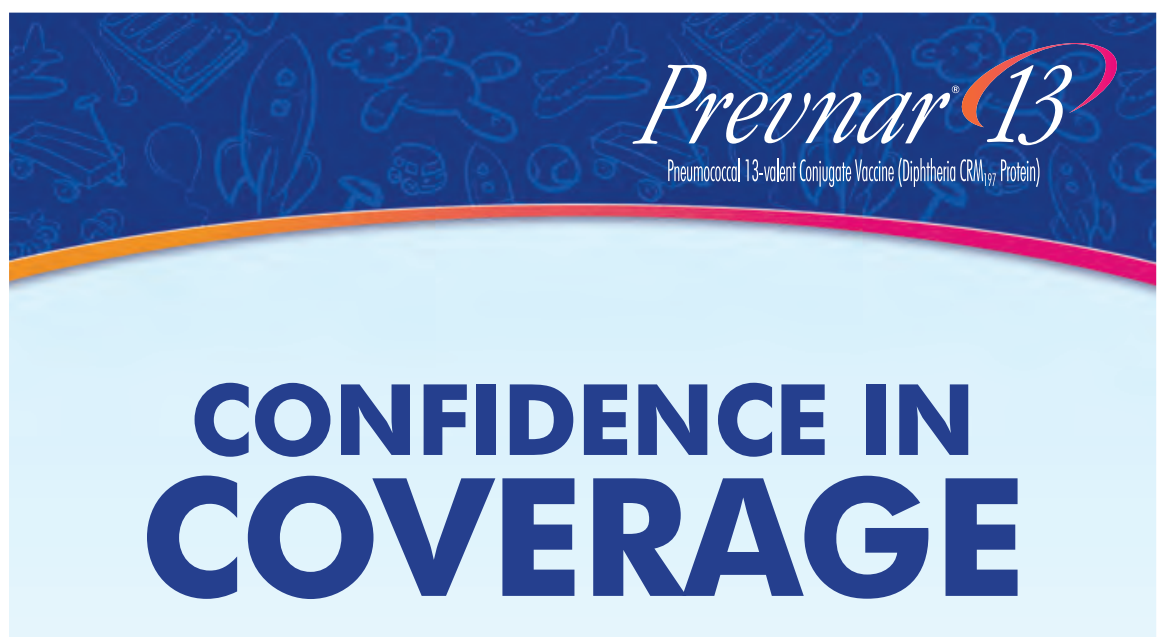

\section{Providing the broadest coverage of $S$. pneumoniae serotypes indicated in a pneumococcal conjugate vaccine $e^{n, 2,3}$}
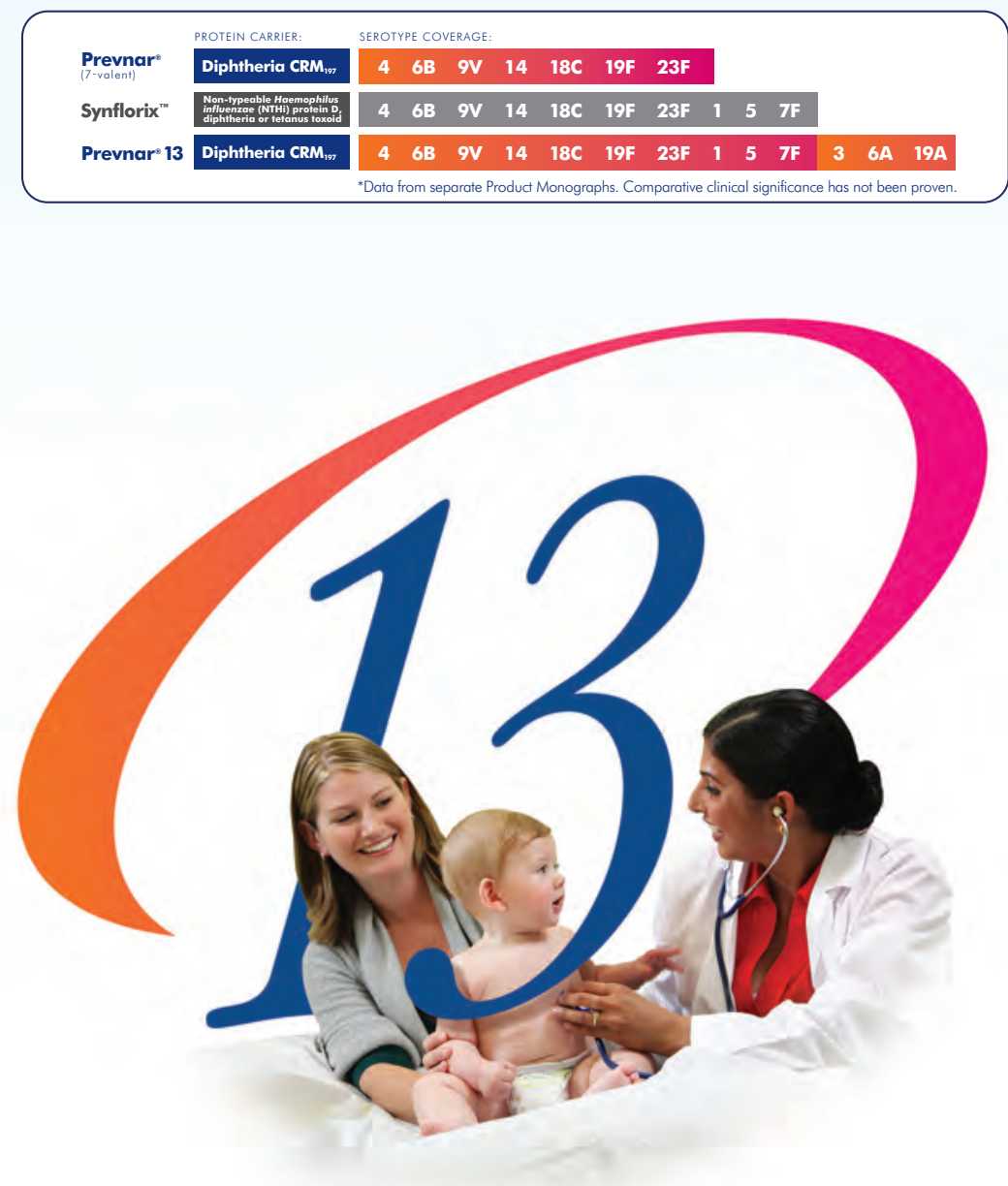

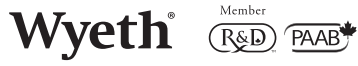

(i) 2010 Wyeth Canada
Montréal, Canada H4R 1 J6

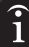




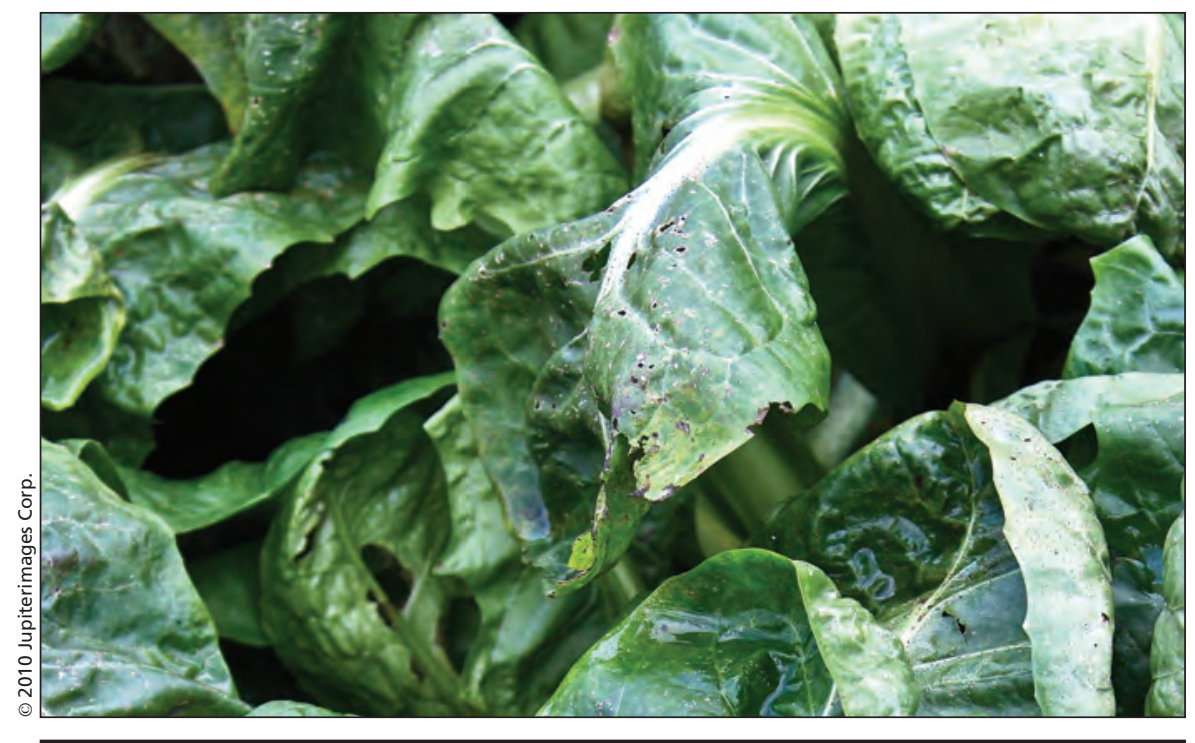

In 2006, Escherichia coli 0157:H7 found in raw spinach in the United States was linked to about 200 illnesses and several deaths.

role in food safety are working together.

Obama issued a statement on July 7 supporting action on the Senate legislation, which he said would complement the efforts of the working group. He said the administration already has taken steps to reduce the prevalence of $E$. coli, implemented new standards to reduce exposure to campylobacter, one of the most common causes of food poisoning, and issued a rule to help control salmonella contamination, the most common cause.

Attorney Bill Marler, whose Seattle law firm specializes in food-related illnesses, says a lack of coordination among state, federal and local governments is one reason that outbreaks of foodborne illnesses aren't identified more quickly.

FDA is "underfunded and understaffed for what we expect them to do and it's only getting worse" as imports increase and food production becomes more complex, Marler says. "The risks are just larger. We've not kept up with the reality of how our food is produced."

Consumer groups, meanwhile, have been trying to increase pressure on Congress to act by stressing public interest in the issue.
Sandra Eskin, director of the Pew Health Group's food safety campaign, says people are shocked to learn the FDA doesn't have authority under 70year-old food safety laws to require recalls, and that food facilities can go a decade between FDA inspections.

Make Our Food Safe, a coalition of consumer, public health and food safety groups, welcomed the committee's recommendation that the FDA be given more authority. It said in a statement that the FDA "desperately needs a specific mandate to prevent foodborne illness rather than continuing to act only after people become sick or die."

The coalition has an ally in Robyn Allgood of Idaho, whose two-year-old son Kyle died in 2006 from eating a spinach smoothie contaminated with E. coli. Allgood recently taped a radio ad urging senators to act on the legislation, and travelled to Washington to press for action.

"No family should have to go through this," Allgood says in the radio ad, paid for by the Pew Charitable Trust. "We can save other children."

The Institute of Medicine and National Research Council are private, nonprofit institutions that provide advice to Congress, which requested the food safety report. - Nancy Benac, Washington, DC

DOI: $10.1503 / \mathrm{cmaj} .109-3317$

\section{Gulf oil spill exposes gaps in public health knowledge}

Previously published at www.cmaj.ca

$\mathrm{T}$ he Gulf of Mexico oil spill set in motion an army of health professionals deployed by Washington, states and centres of medical learning, all dedicated to helping Americans stay well in the throes of the catastrophe and its aftermath.

For all that effort, an unsettling reality sank in even before the undersea rupture was staunched: Science knows precious little about the human hazards of exposure to crude oil. Researchers have a better understanding of oil's per- ils for pelicans and marshlands of the Louisiana bayou.

In the short term, the health effects have been most obvious among the thousands of workers scrambling to contain and now clean up the spill. They've worked in brutal heat for months, face to face with the primal sludge, in conditions too steamy for many to wear full protective gear. They've experienced respiratory problems, skin irritation and plenty of heat stress.

Much less clear is the impact the chemical cocktail in Gulf crude will have on the public in years to come.
Gulf states have now become a living laboratory as teams of medical professionals lay the foundation for long-term monitoring of the population.

At congressional hearings in Washington, DC, and an Institute of Medicine conference convened in New Orleans, Louisiana, as the oil still flowed, experts expressed frustration that they know little about the health risks of a substance that courses so ubiquitously through daily life.

"While extensive data exists on the effects of oil spills on wildlife and ecosystems, the effects on human health 